\title{
PLATELET LEUCOCYTE AGGREGATES ANALYSIS IN LEUCODEPLETED AND NONLEUCODEPLETED PLATELET CONCENTRATES
}

\author{
Teguh Triyono, Raehanul Bahraen \\ Department of Clinical Pathology dan Laboratory Medicine, Faculty of Medicine, Gajah Mada University/Dr. Sardjito Hospital Yogyakarta, \\ Indonesia.E-mail: pakteguhtri@yahoo.com
}

\section{ABSTRACT}

Activated platelet could initiate aggregation and linkage with nearby leucocytes to form Platelet-Leucocyte Aggregates (PLA). Leucodepletion procedure removes leucocyte and separate it from the other blood components. Leucodepletion reduces the probability of PLA formation. This study aimed to analyze the percentage difference of PLA in leucodepleted and nonleucodepleted platelet concentrate. Dual expression of CD41 and CD45 was determined by flow cytometry method representing the value of PLA, PLA percentage of each group was calculated and analyzed with statistical software SPSS 22. Mean percentage value of PLA in the leucodepleted group was $63.05 \pm 19.86$, meanwhile in the nonleucodepleted group was $64.61 \pm 17.27$. The percentage of PLA in the nonleucodepleted group is higher than leucodepleted although the difference is not statistically significant.

Key words: Platelet-leucocyte aggregates, leucodepletion, platelet concentrates

\section{INTRODUCTION}

Platelet transfusion is indicated for the prevention and treatment of bleeding problems in a patient with thrombocytopenia or any functional platelet disorders. Platelet concentrates preparation contains a large number of platelets and lacking the other blood components; therefore reducing the risk of transfusion-related adverse events for recipients after the donation process. Adverse events related to platelet transfusions are alloimmunization, transmissible transfusion infection and allergic reaction. ${ }^{1}$

Inflammatory state of blood systems and disruption in vessel wall integrity can trigger platelet activation. Activated platelet will initiate the formation of platelet aggregates and promote adherence to the subendothelial matrix. This cascade of events can occur in hemostasis, physiologic and pathologic conditions. Activated platelet is also capable of sticking to any kinds of leucocyte and form Platelet-Leucocyte Aggregates (PLA) locally or in systemically. ${ }^{2-4}$

Platelet-leucocyte aggregates plays a role and influence in the progression of several inflammatory diseases and destruction of a blood vessel (i.e., stroke, inflammatory bowel disease, and ischemic vascular risk). The increasing level of PLA can be found in those situations, and some research evidence are showing a correlation between the elevation of PLA level and incidence of those diseases. Platelet leucocyte aggregates can be used as a parameter to assess the severity of diseases and monitor diseases progression. ${ }^{2-4}$

CD45 is a tyrosin phosphatase-related protein receptor which is expressed by all leucocytes. CD45 has a vital role in leucocyte function especially, T-cell. CD41 is a transmembranous glycoprotein expressed by platelet and megakaryocytes. It has been reported that CD41 also expressed by other hematopoietic progenitor cells. CD41 plays a part in adhesion and aggregation of platelet. It is, an insult toward CD41 can cause coagulation dysfunction. ${ }^{5,6}$

Leucodepletion is a technique to remove/reduce the number of leucocytes from the blood product. Contaminant leucocytes within transfused blood products can trigger several adverse events i.e. transmission of an agent of infection, febrile non-hemolytic transfusion reaction, and immunosuppression. Utilization of leucodepleted blood component can minimize the risks above. The benefit is higher for large volume transfusion in case of renal transplant and immunosuppressive. The usage of leucodepleted blood products is controversial from the view of cost-effectiveness. In America and several European countries, 
leucodepletion had to be done for all blood products. ${ }^{7.8}$

The considerably high number of leucocyte contaminants present in platelet concentrate that should be separated from the other blood components to yield leucodepleted blood product. Even so, there is still a probability of PLA remains in each platelet concentrate. In this study, we seek to compare the percentage difference of PLA between leucodepleted and nonleucodepleted platelet concentrates.

\section{METHODS}

It is an analytic cross-sectional study design in which the sampling of platelet concentrate was done before transfusion. Facs Calibur flow cytometry method analyzed dual expression of CD41 and CD45 which showed interlinkage of platelet and leucocyte. Dual expression of CD41 and CD45 represented the value of PLA in the platelet concentrate. Percentage of PLA was determined as a comparison of total PLA (dual expression of CD41 and CD45) with a total number of leucocytes (CD45 expression). Analysis of the mean percentage difference of PLA between each group was carried out using independent student T-test SPSS ver 22 software with the significance level set at $p<0.05$. The Ethics Committee of Faculty Medicine of Universitas Gadjah Mada Yogyakarta ethically approved this study (number KE/FK/426/EC).

\section{RESULT AND DISCUSSION}

Sixty-two units of platelet concentrate consist of 28 leucodepleted, and 34 nonleucodepleted units were obtained in this study. Platelet-leucocyte aggregates was depicted in the dual expression area of CD41 and CD45, as shown in Figure 1.

Mean percentage value of PLA in leucodepleted group was 63.05 with a Standard Deviation (SD) of 19.86, while in the nonleucodepleted group was 64.61 with SD of 17.27 (Table 1).

There was found that PLA percentage in the nonleucodepleted group was higher than the leucodepleted group. Leucodepleted product contains a fewer number of leucocyte as result of previous leucocyte removal procedures; therefore the probability of PLA formation is lower. This finding could be served as fundamental consideration for the utilization of leucodepleted product in blood transfusion, especially platelet concentrate as stated by previous researches. Utilization of

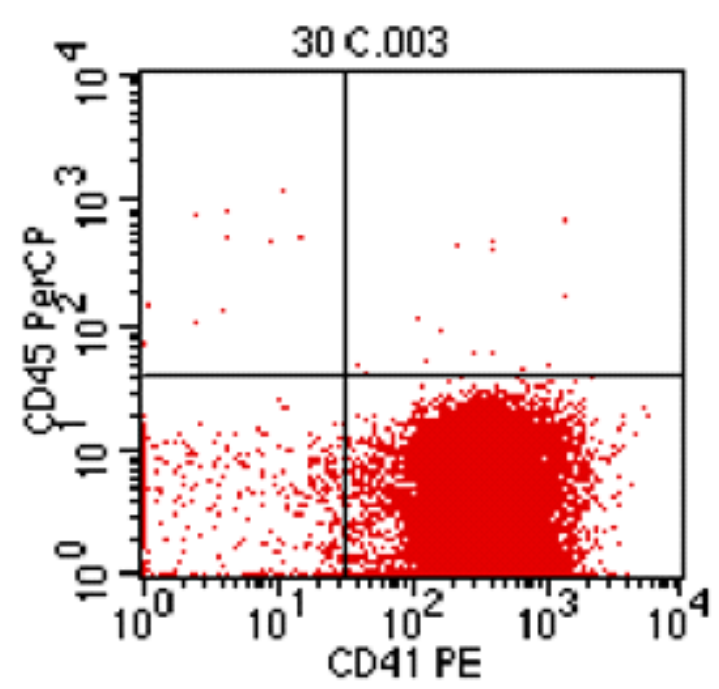

Figure 1. Scatter plot expression CD45 and CD41. Platelet-leucocyte aggregates are shown in the top-right quadrant as CD45+/CD41+

Table 1. PLA percentage of the leucodepleted vs. nonleucodepleted group

\begin{tabular}{lccc}
\hline Group & n & Mean & SD \\
\hline Leucodepleted & 28 & 63.05 & 19.86 \\
Nonleucodepleted & 34 & 64.61 & 17.27 \\
\hline
\end{tabular}

leucodepleted component can minimize several blood transfusion-related adverse events, especially for a patient who need large volume blood transfusion such as chronic renal failure. ${ }^{4,7,8}$

Percentage of PLA in each group, either leucodepleted or nonleucodepleted, was not differ significantly $(p>0.05)$. Several previous research findings, showed a clinically significant difference in a patient who received leucodepleted component transfusion over nonleucodepleted. It was reported that leucodepleted product could minimize febrile non-hemolytic transfusion reaction, alloimmunization, platelet refractoriness (for a patient with large volume transfusion) as well as prevent transmission of EBV and CMV. Furthermore, the utilization of leucodepletion can reduce the incidence of infection and MODS in case of sepsis. Therefore leucodepleted product can become an alternative of choice for blood transfusion. ${ }^{9,10}$

There are some possibilities which can influence the comparison of PLA in leucodepleted and nonleucodepleted platelet concentrate. First, the 
storage process of blood product like platelet concentrate. Platelet is easily damaged if situated outside our body and will lose its a function if stored $>24$ hours with improper temperature handling, which will accelerate the process of platelet destruction. Storage of platelet also promote the formation of aggregates. Therefore platelet transfusion should be done as soon as possible after collection of blood from a donor and should not be kept longer than five days at $20-24^{\circ}$ Celcius. ${ }^{11}$ Longer duration of storage can cause aggregate formation including PLA, therefore it highly likely that PLA could be formed as the result of long storage time. Second, the existence of several chemical products that produced either by leucocyte or thrombocyte which triggered the activation of thrombocyte and eased the formation of PLA. Third, the ratio amount of thrombocyte and leucocyte is so big. For example: In the adult male, normally average thrombocyte count is $250-450$ thousand/ $\mu \mathrm{L}$ whereas average leucocyte count is approximately $9000-11000 / \mu \mathrm{L}$. Platelet-Leucocyte Aggregates formed by bonding of platelet and leucocyte, with the huge ratio of thrombocyte to leucocyte made the ratio percentage of PLA may be not significant.

\section{CONCLUSION AND SUGGESTION}

Based on this study, there was found that the percentage of PLA in nonleucodepleted is higher than leucodepleted group although the difference is not statistically significant. The researchers consider the utilization of leucodepleted platelet concentrate for transfusion to minimize the risk of the adverse event, one of which is PLA formation.

In the future, it is expected that further research can prove the impact of in vivo PLA formation in recipients. Therefore, the role of the PLA in transfusion would be more clearly defined.

\section{REFERENCES}

1. Kelsey CP. Guidelines for the use of platelet transfusions. J British Haematology, 2003; 122(1): 10-2.

2. Schmalbach B, Stepanow O, Jochens A, Riedel C, Deuschi G, Kuhlenbäumer G. Determinants of platelet-leukocyte aggregation and platelet activation in stroke. Cerebrovasc Dis, 2015; 39(3-4): 176-180.

3. Cerletti C, Tamburrelli C, Izzi B, Gianfagna F, de Gaetano G. Platelet-leukocyte interactions in thrombosis. Thrombosis Research, 2012, 129(3): 263-266.

4. Glu YT, Uzun H, Gucer H. Circulating platelet-leukocyte aggregates in patients with inflammatory bowel disease. J Chinese Med, 2012; 182-5.

5. Altin JG, Sloan EK. Immunology, and cell biology: The role of CD45 and CD45-associated molecules in T cell activation. Canberra J, 1997; 75(5): 430-45.

6. Anonim. PE Anti-mouse CD41 antibody. Available from URL:http://www.biolegend.com/ pe-anti-mouse-cd41 antibody-5897.html. Accessed August 22, 2015.

7. Chu RW. Leukocytes in blood transfusion: Adverse effects and their prevention. HKMJ, 1999; 5: 280-4.

8. Singh S, Kumar A. Leukocyte depletion for safe blood transfusion. Biotechnol J. 2009; 4(8): 1140-51. Available from URL: http://www.ncbi.nlm.nih.gov/ pubmed/19418471. Accessed August 23, 2015.

9. Sharma RR, Marwaha N. Leukoreduced blood components: Advantages and strategies for its implementation in developing countries. Asian J.T. 2010; 4(1): 3-8. Available from URL: http://www.ncbi.nlm.nih.gov/pmc/articles/PMC2847 337/. Accessed September 8, 2015.

10. Tanaka S, Harrois A, Duranteau J. Lekodepleted versus nonleukodepleted red blood cell transfusion in septic patients: A microcirculatory vision. Critical Care J, 2014; 18(1): 128.

11. Anonim, Digital library UNIMUS, available from URL:http://digilib.unimus.ac.id/files/disk1/115/jtptun imus-gdl-onysuci-5726-3-3.babii-i.pdf. Accessed September 8, 2015 